\title{
PENGUJIAN HIPOTESIS STATISTIK PENGGUNAAN WARNA CAT TERHADAP PENGARUH HARGA JUAL MOBIL
}

\author{
Hidayat Muhammad Nur ${ }^{1}$, Vadlya Maarif ${ }^{2}$ \\ ${ }^{1}$ Sistem Informasi, Universitas Bina Sarana Informatika \\ ${ }^{2}$ Sistem Informasi, STMIK Nusa Mandiri Jakarta \\ e-mail : ${ }^{1}$ hidayat.hmm@bsi.ac.id, ${ }^{2}$ vadlya.vIr@nusamandiri.ac.id
}

\begin{abstract}
In Indonesia there are several types of cars that are marketed such as LCGC (Low Cost Green Car), Hatchback, Sedan, MPV (Multi Purposes Vehicle), SUV (Sport Utility Vehicle), and Crossover. In addition to types and facilities, car manufacturers also apply different prices for certain types of paint-colored cars. Knowing the reasons for car manufacturers in distinguishing prices from the colors of paint used is not yet sufficiently understood. There are 7 color variants namely Crystal Black Pearl, White Orchid Pearl, Modern Steel Metallic, Red Rallye, Lunar Silver Metallic, Deep Ocean Blue and Purplish Gray Metallic. Special White Orchid Pearl colors are subject to an additional fee of Rp. 3 million, and in addition to the color Rallye Red is subject to an additional fee of Rp.1.5 million from the initial price of Rp.381.5 Million (OTR) for type 1.8 L and P-CVT. Each car manufacturer has its own distinctive color. Therefore, this study provides an analysis of the decision of the producer to provide the selling price of the car calculated using the SWOT method. The coordinates of the probability (O) and strength (S) of producer $\mathrm{H}$ are found, meaning that they support an aggressive strategy of producing cars with color variants and quantitative results of the statistical hypothesis showing a positive correlation, with a scale of KR 0.95 .
\end{abstract}

Keywords-SWOT, Correlation Coefficient, Hypothesis Statistics, Car Paint Color, Effect of Car Selling Prices.

Abstrak - Di Indonesia ada beberapa tipe mobil yang dipasarkan seperti LCGC(Low Cost Green Car), Hatchback, Sedan, MPV(Multi Purposes Vehicle), SUV(Sport Utility Vehicle), dan juga Crossover. Selain tipe dan fasilitas, produsen mobil juga menerapkan harga berbeda untuk tipe mobil berwarna cat tertentu. Mengetahui alasan produsen mobil dalam membedakan harga dari warna cat yang digunakan belum cukup dipahami. Terdapat 7 varian warna yaitu Crystal Black Pearl, White Orchid Pearl, Modern Steel Metallic, Rallye Red, Lunar Silver Metallic, Deep Ocean Blue dan Purplish Gray Metallic. Khusus warna White Orchid Pearl dikenakan biaya tambahan sebesar Rp.3 juta, dan selain warna Rallye Red dikenakan biaya tambahan sebesar Rp.1,5 juta dari harga awal Rp.381,5 Juta (OTR) untuk type $1.8 \mathrm{~L}$ dan P-CVT. Tiap produsen mobil memiliki ciri khas warna masing - masing. Oleh karena itu, penelitian ini menyampaikan analisa keputusan produsen memberikan harga jual mobil dihitung menggunakan metoda SWOT. Didapati kordinat kuadran peluang(O) dan kekuatan(S) dari produsen $\mathrm{H}$, artinya mendukung strategi agresif memproduksi mobil dengan varian warna dan hasil kuantitatif hipotesis statistik menunjukkan korelasi bersifat positif, dengan skala KR 0,95.

Kata kunci-SWOT, Koefisien Korelasi, Statistik Hipotesis, Warna Cat Mobil, Pengaruh Harga Jual Mobil.

\section{A. PENDAHULUAN}

Produsen mobil $\mathrm{H}$ mempunyai 7 varian warna, dalam mengelola varian warna yang direspon calon pembeli membutuhkan sebuah sistem dan informasi untuk dukungan pekerjaan yang berlangsung akan berkontribusi terhadap kelancaran seluruh operasi pada suatu perusahaan.

Para calon pembeli sangat memperhatikan keindahan desain dan penggunaan warna cat mobil. Ini menjadi kajian produsen mobil untuk menentukan ciri khas warna mobil untuk di produksi, karena itu sebagai tujuan penelitian ini, baik faktor internal maupun eksternal mempengaruhi penentuan harga jual mobil dan layak di lakukan pengujian secara hipotesis statistik guna acuan pengambilan keputusan yang baik.

Penggunaan analisa SWOT (Rangkuti 03:19) sebagai tolak ukur dari sudut pandang pembeli mengenai pengaruh warna cat. Yang nantinya akan digunakan produsen untuk menentukan desain juga penggunaan warna dalam mobil yang diproduksi. Ditambah diuji berdasarkan data empiris, yaitu berdasarkan apa yang dapat diamati dan dapat diukur. 


\section{B. TINJAUAN PUSTAKA}

Belum banyak yang membahas tentang pengaruh warna cat terhadap harga jual mobil, namun hakikatnya hampir sama seperti semakin suatu barang disukai, maka harganya pun akan semakin naik, sama halnya dengan mobil. Hipotesis statistik menyatakan hasil observasi tentang populasi (benda) dalam bentuk kuantitatif. (Nasution, S, 44:2004)

\section{Tinjauan studi:}

1. Jenis cat mobil yang dimuat pada situs Aneka Tips Harian ada 3 (tiga), diantaranya : Urethane, Metalik, dan Glossy. Ketiganya memiliki ciri khas masing-masing.

Urethane memiliki ciri khas dengan hasil yang mengkilap sehingga memiliki kesan yang mewah dan cocok untuk mobil mewah.

Metalik memiliki ciri khas pearl (mutiara) dengan hasil yang mengagumkan untuk menjadikan tipe mobil sport lebih gagah. Berbeda halnya dengan Urethane yang memiliki harga lebih murah dari Metalik karena hanya memiliki efek mengkilap.

Glossy merupakan jenis cat paling sederhana karena tidak memiliki efek tambahan apapun.

2. Berdasar warna dari berbagai jenis cat, tentu mempengaruhi harga. Termuat pada Bukalapak.com, jenis Urethane memiliki harga kisaran Rp 135.000/liter.

Sedangkan jenis cat Metalik memiliki harga Rp.150/250 ml.

Berbeda jenis cat Glossy yang memiliki harga termurah yaitu kisaran $\mathrm{Rp}$ $100.000 / \mathrm{kg}$.

3. Menurut situs Bahasotomotif.com, ada 6 pengaruh harga jual suatu mobil diantaranya brand image, warna cat, daya tahan, ketersediaan onderdil, model, teknologi, dan bbm. Warna cat yang dimaksud adalah warna favorit konsumen seperti hitam, silver dan putih. Melihat fenomena tersebut, tentu produsen mempertimbangkan penggunaan jenis cat dengan kualitas bagus seperti Urethane dan Metalik. Tentunya produsen tetap memproduksi mobil dengan cat kualitas rendah seperti Glossy untuk konsumen yang menginginkan harga yang terjangkau daripada hasil yang diperoleh.

\section{Keaslian penelitian:}

Identifikasi mengenai pengaruh harga jual mobil membentuk pandangan kepada konsumen untuk mengetahui hal-hal yang jarang diketahui konsumen. Penggunaan metode SWOT dimaksudkan untuk mengetahui beberapa faktor yang bisa digunakan sebagai landasan teori mengenai pengaruh warna cat sendiri.

Setelah hal tersebut tercapai, selanjutnya dilakukan pengujian hipotesis statistik dan skala guttman untuk memperjelas hasil penelitian yang dilakukan. (Nasution, S, 68:2004)

\section{METODE PENELITIAN}

Metode penelitian yang digunakan guna mengetahui strategi yang pas untuk menciptakan kepuasan pelanggan dari segi keindahan desain juga warna yang digunakan. Tentu banyak faktor yang mempengaruhi penentuan harga, namun dalam hal ini faktor yang ditonjolkan adalah penggunaan jenis dan warna cat.

\section{Penggunaan metode SWOT}

Membentuk prioritas yang menyusun hasil penelitian untuk memberikan keterangan kepada konsumen melalui beberapa hal, diantaranya:

a. Analisis produsen mengenai faktor yang mempengaruhi penentuan harga mobil berikut bukti konkret. Dilanjutkan penjelasan detail masing-masing faktor untuk mempermudah pengolahan penentuan hasil pada tahap selanjutnya.

b. Analisis SWOT mengenai mobil yang didasari warna cat dengan mencari kelebihan, kelemahan, peluang dan ancaman yang mungkin terjadi.

c. Matrix kesimpulan analisis SWOT yang dituangkan ke dalam tabel untuk pembobotan.

\section{Hipotesis Statistik}

Digunakan untuk menyatakan ada hubungan antara variabel atau lebih dari dua variabel. Tingkat hubungan jumlah carian warna cat dan jumlah calon pembeli mobil. Jika Bahwa terdapat jumlah volume calon pembeli dengan bertambahnya varian warna cat, maka dikatakan korelasi ( $r$ ) atau hubungan positif. Jumlah kendaraan bervarian warna dapat pula dicari hubungungan dengan contoh ketentraman hidup. Jika bahwa ketentraman hidup berkurang dengan meningkatnya jumlah varian warna, maka dikatakan korelasi negatif.

Tingkat korelasi dinyatakan dengan angka atau koefisien. Koefisien korelasi berkisar antara -1.00 sampai +1.00 . Hubungan antara dua variabel di lambangkan sebagai $\mathrm{Ho}: r_{\mathrm{xy}}=$ 0 artinya hipotesis menyatakan tidak ada korelasi antara variabel $X$ dan $Y$. Setiap Korelasi yang berbeda dengan 0 jadi $\mathrm{H} ; \mathrm{r}_{\mathrm{xy}} \neq 0$ menunjukkan adanya korelasi yang dapat 
dihitung besarnya, yang bersifat negatif atau positif.

\section{Penggunaan metode Skala Guttman}

Skala ini bertujuan untuk menentukan hingga manakah suatu skala sikap berdimensi satu atau unidimensional. Artinya skala ini mengukur dimensi yang sama dari sikap tertentu dalam berbagai intensitas, dari yang paling kuat atau tinggi sampai yang paling lemah atau rendah.

Rumus Guttman Koefisien Reproducibilitas $(\mathrm{KR})$, ialah:

$$
\mathrm{KR}=1-\underset{\text { jumlah penyimpangan }}{\text { jumlah respons }}
$$

Dimana Nilai KR menurut Guttman hendaknya harus 0,90 atau lebih.

\section{Kerangka pendekatan:}

Dalam penelitian yang dilakukan terdapat kerangka pikir sebagai gambaran singkat, seperti pada gambar di bawah ini :

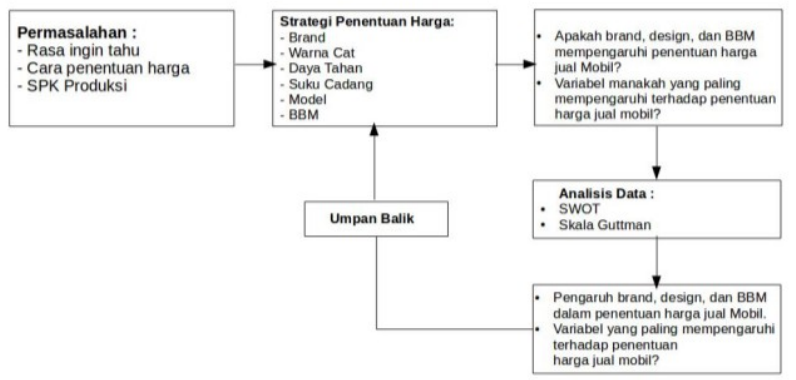

Gambar III.1.Kerangka Pendekatan

Pada gambar tersebut dijelaskan bahwa permasalahan utama ada pada rasa ingin tahu, cara penentuan harga dan Sistem Pengambilan Keputusan. Diperlukan riset penelitian memecahkan masalah tersebut. Terdapat faktor yang mempengaruhi dan variabel utama dalam penentuan harga jual mobil.

\section{HASIL DAN PEMBAHASAN}

Mengetahui kriteria dalam penentuan harga jual suatu mobil adalah tujuan dari awal penelitian ini. Jenis mobil yang kami gunakan adalah 1,8 L dan P-CVT. Beberapa variabel yang sudah tersusun kemudian diberikan pembobotan untuk mengetahui seberapa besar pengaruhnya terhadap penentuan harga.

Populasi menurut Sugiyono (2004:72), adalah wilayah generalisasi yang terdiri dari subyek atau subyek yang mempunyai kualitas dan karakteristik tertentu ditentukan oleh peneliti untuk dipelajari dan kemudian ditarik kesimpulan.

\section{Pengelompokan Populasi data}

Pengelompokan data yang digunakan adalah koresponden yang mengetahui mengenai dunia mobil, antara lain :

1. Dealer(10 orang)

2. Pengguna $1,8 \mathrm{~L}$ (20 orang)

3. Pengusaha cat mobil(2 orang)

\section{Pembahasan}

Variabel yang tercantum sebagai alternatif penentuan solusi adalah hasil observasi dengan koresponden sehingga didapati perolehan data yang bisa digunakan, meliputi :

a. Analisis faktor eksternal

Analisis faktor eksternal SWOT disusun ke dalam bentuk sebuah matriks. Dalam analisa faktor eksternal sebagai ukuran dipengaruhi oleh beberapa faktor, karenanya dibentuk matrik langkah-langkah SWOT untuk memudahkan analisis sebagai berikut : Tabel IV.1. EFAS

\begin{tabular}{|c|c|c|c|c|}
\hline $\begin{array}{l}\text { Faktor Strategi Eksternal } \\
\text { (1) }\end{array}$ & $\begin{array}{l}\text { Bobot } \\
\text { (2) }\end{array}$ & $\begin{array}{l}\text { Rating } \\
\text { (3) }\end{array}$ & $\begin{array}{l}\text { Bobot X Rating } \\
\text { (4) }\end{array}$ & $\begin{array}{l}\text { Komentar } \\
\text { (5) }\end{array}$ \\
\hline \multicolumn{5}{|l|}{ Peluang: } \\
\hline - Gengsi Pembeli & 0,85 & 3 & 2,55 & Target \\
\hline - Pecinta Mobil crossover & 1,0 & 2 & 2,0 & Target \\
\hline - Persaingan pasar sedikit & 0,50 & 4 & 2,0 & Peluang \\
\hline - Keindahan desain & 0,75 & 4 & 3,0 & Ciri khas \\
\hline - Kesan Mewah & 1,0 & 3 & 3,0 & Ciri khas \\
\hline \multirow{6}{*}{$\begin{array}{l}\text { Ancaman: } \\
\text { - Keluhan pelanggan } \\
\text { - Perubahan selera konsumen } \\
\text { - Pandangan konsumen } \\
\text { - Persaingan pasar } \\
\text { Produk ditiru }\end{array}$} & & & & \\
\hline & 0,25 & 2 & 0,50 & Permasalahan \\
\hline & 0,75 & 2 & 1,5 & Tantangan \\
\hline & 0,35 & 2 & 0.70 & Bervariasi \\
\hline & 0,45 & 2 & 0,90 & Tantangan \\
\hline & 0,50 & 2 & 1,0 & Kreatifitas \\
\hline Total: & 6,4 & & 17,15 & \\
\hline
\end{tabular}

b. Analisis faktor internal Analisis faktor internal SWOT disusun ke dalam bentuk sebuah matriks. Dalam analisa faktor eksternal sebagai ukuran dipengaruhi oleh beberapa faktor, karenanya dibentuklah suatu matrik langkah-langkah SWOT untuk memudahkan analisis sebagai berikut : Tabel IV.2. IFAS

\begin{tabular}{|c|c|c|c|c|}
\hline $\begin{array}{l}\text { Faktor Strategi Internal } \\
\text { (1) }\end{array}$ & $\begin{array}{l}\text { Bobot } \\
\text { (2) }\end{array}$ & $\begin{array}{l}\text { Rating } \\
\text { (3) }\end{array}$ & $\begin{array}{l}\text { Bobot X } \\
\text { Rating } \\
\text { (4) }\end{array}$ & $\begin{array}{l}\text { Komentar } \\
\text { (5) }\end{array}$ \\
\hline \multicolumn{5}{|l|}{ Kekuatan : } \\
\hline - Reputasi & 1,0 & 4 & 4,0 & Keunggulan \\
\hline - Desain & 0,55 & 3 & 1,65 & Bertahap \\
\hline - Engine & 0,75 & 3 & 2,25 & Komponen tetap \\
\hline - Kualitas cat & 0,75 & 3 & 2,25 & Komitmen \\
\hline - Warna yang disediakan & 0,25 & 2 & 0,50 & Komitmen \\
\hline \multirow{6}{*}{$\begin{array}{l}\text { Kelemahan : } \\
\text { : Harga mobil } \\
\text { : Karna cat tipe terendah } \\
\text { - Remponenen ringkih } \\
\text { - Konsumsi bbm boros }\end{array}$} & & & & \\
\hline & 1,0 & 1 & 1,0 & Ketetapan \\
\hline & 0,50 & 1 & 0,5 & Alternatif pilihan \\
\hline & 0,30 & 1 & 0,30 & Pengaturan pabrik \\
\hline & 0,20 & 1 & 0,20 & Proses \\
\hline & 0,50 & 2 & 1,0 & Standar penggunaan \\
\hline Total : & 5,8 & & 12,65 & \\
\hline
\end{tabular}


1. Analisis gabungan EFAS dan IFAS

Setelah tabel EFAS dan IFAS ada, kemudian digabungkan untuk menghasilkan data sebagai berikut :

Tabel IV.3. Analisis Gabungan EFAS dan IFAS

\begin{tabular}{|c|c|c|c|}
\hline Strenghts (Kekuatan) & Skor & Weakness (Kelemahan) & Skor \\
\hline $\begin{array}{ll} & \text { Reputasi (s1) } \\
: & \text { Desain (s2) } \\
: \text { Engine (33) } \\
: \text { Kualtas cat (o4) } \\
\text { Warna yang disediakan (s5) }\end{array}$ & $\begin{array}{l}4,0 \\
1,65 \\
2,25 \\
2,25 \\
0,50\end{array}$ & $\begin{array}{ll} & \text { Harga mobil (w1) } \\
: & \text { Warna cat tipe terendah (w2) } \\
: & \text { Komponen rigkih (w3) } \\
: & \text { Regenerasi lama (w4) } \\
\text { - Konsumsi bom boros (w } 5 \text { ) }\end{array}$ & $\begin{array}{l}1,0 \\
0,5 \\
0,30 \\
0,20 \\
1,0\end{array}$ \\
\hline Sub total S & 10,65 & Sub total W & 3 \\
\hline Opportunities (Peluang) & Skor & Threats (Ancaman) & Skor \\
\hline 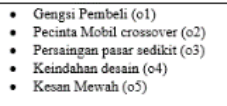 & $\begin{array}{l}2,55 \\
2,0 \\
2,0 \\
3,0 \\
3,0\end{array}$ & 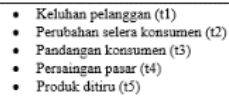 & $\begin{array}{r}0,50 \\
1,5 \\
0,70 \\
0,90 \\
1,0\end{array}$ \\
\hline Sub total 0 & 12,55 & Sub total T & 4,6 \\
\hline Total $\mathrm{S}+\mathrm{O}$ & 23,2 & Total $\mathrm{W}+\mathrm{T}$ & 7,6 \\
\hline
\end{tabular}

Setelah sub total EFAS dan sub total IFAS disusun menjadi tabel EFAS dan IFAS kemudian dijumlahkan Kekuatan (S) ditambahkan dengan Peluang $(\mathrm{O})$ ternyata memiliki jumlah nilai $=10,65+12,55=23,3$ hasilnya lebih besar $(>)$ dari total Kelemahan(W) dan Ancaman(T) yaitu $3+4,6=7,6$. Dari hasil tersebut didapati bahwa warna cat turut mempengaruhi penetapan harga jual mobil. Tidak hanya cat, fitur dan desain pun juga turut menambah nilai jual pada mobil 1,8 L. Dari skor total ini, maka dapat digambar Matrik SWOT yang dapat dilihat pada gambar 2 sedangkan untuk mencari koordinatnya, dapat dicari dengan cara berikut :

Koordinat analisis internal:

(Skor total Kekuatan - Skor total Kelemahan): 2 = $(10,65+3): 2=6,8$

Gambar 2. Koordinat analisis internal

Koordinat analisis eksternal :

(Skor total Peluang - Skor total Ancaman): 2 = $(12,55+4,6): 2=8,5$

Gambar 3. Koordinat analisis eksternal

Jadi, titik koordinat terletak pada : $(6,8 ; 8,5)$

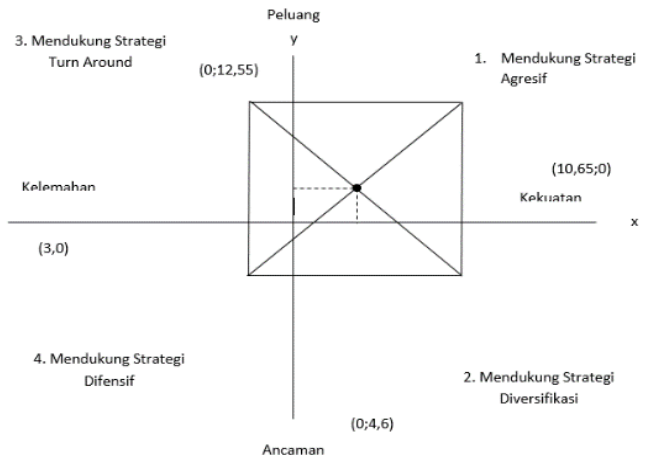

Gambar IV.1 Koordinat Matrik SWOT
2. Analisis alternatif matriks SWOT

Tabel IV.4. Koordinat Matrik SWOT

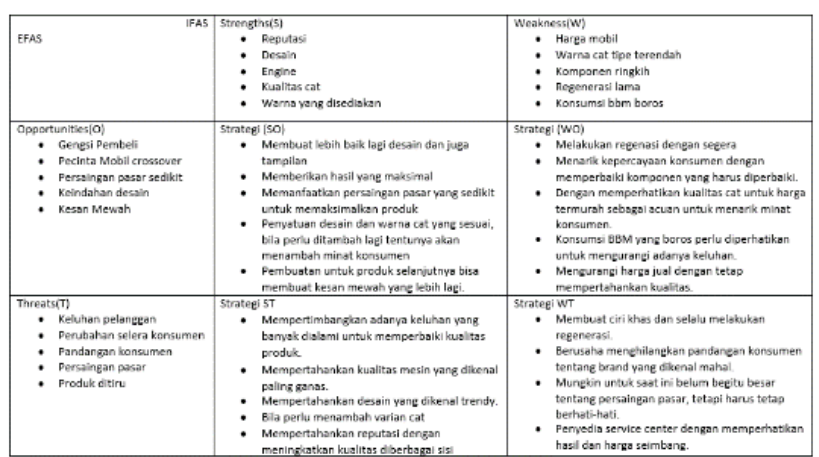

Keterangan :

a. Strategi SO (yang menggunakan kekuatan untuk memanfaatkan peluang)

b. Strategi ST (yang menggunakan kekuatan untuk mengatasi ancaman)

c. Strategi WO (yang meminimalkan kelemahan untuk memanfaatkan peluang)

d. Strategi WT (yang meminimalkan kelemahan untuk menghindari ancaman)

Mengetahui pernyataan hasil observasi tentang populasi benda dalam bentuk kuantitatif dalam penentuan harga jual suatu mobil berdasar varian warna cat adalah tujuan kedua penelitian ini.

Analisa hubungan atau korelasi digunakan untuk mengetahui hubungan antara dua variabel. Misalkan $X$ dan $Y$ adalah dua variabel yang berbeda. $X$ dan $Y$ berhubungan positif apabila kenaikan/pertambahan nilai pada variabel $X$ akan di ikuti kenaikan /pertambahan nilai pada variabel $Y$. Sebaliknya apabila kenaikan/ pertambahan nilai pada variabel $X$ di ikuti penurunan/ pengurangan nilai variabel $Y$ kedua variabel memiliki hubungan negatif.

Kuat lemahnya hubungan di ukur dengan nilai koefisien korelasi $r$, yang kisaran nilainya 0 sampai 1 , untuk hubungan positif dan nilai 0 sampai -1 untuk hubungan negatif. 
Tabel IV.5. Langkah uji hipotesis korelasi:

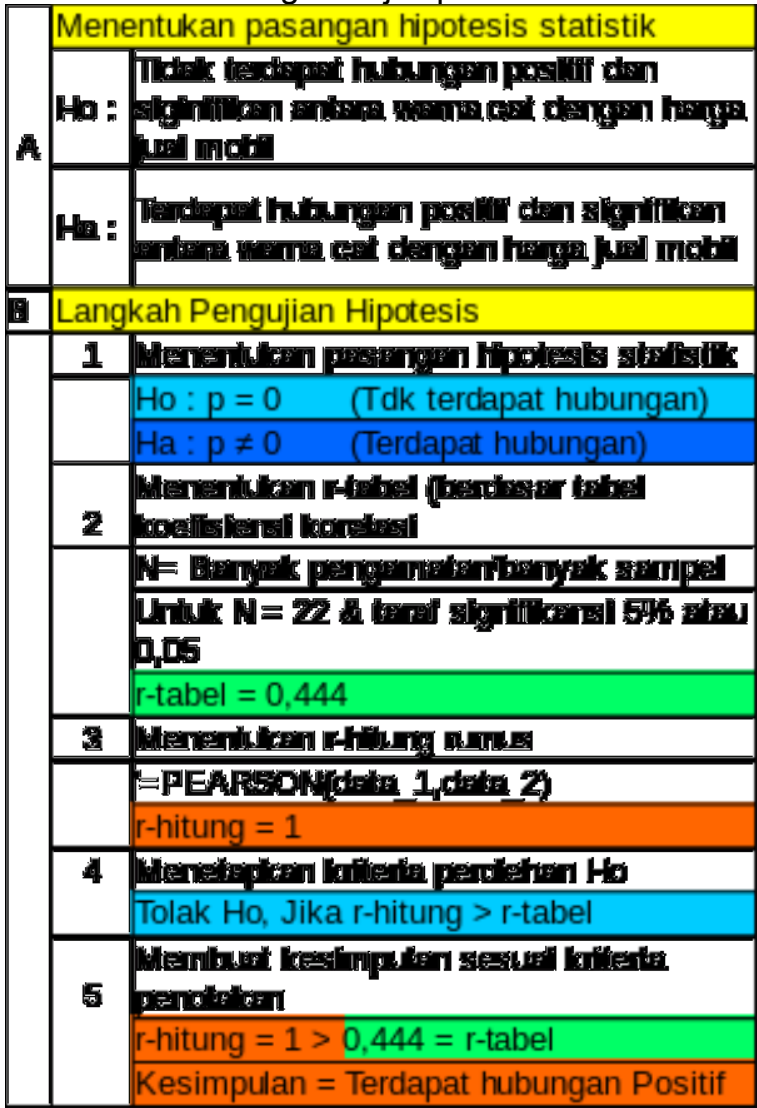

Tujuan ketiga penelitian menggunakan Skala ini untuk menentukan skala sikap berdimensi satu atau unidimensional. Dengan cara sebagai berikut :

1. Menyusun lima pernyataan dengan intensitas (No.1, 2, 3, 4, 5)

2. Responden yang menyetujui dan menerimapernyataan No.1 (paling kuat intensitasnya) dengan sendirinya akan menerima pernyataan No. 2 dan seterusnya.

3. Membuat Skologram
Tabel IV.6. Skologram

\begin{tabular}{|c|c|c|c|c|c|c|}
\hline \multirow{2}{*}{ 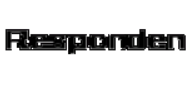 } & \multicolumn{5}{|c|}{ Permuntarin } & \multirow{2}{*}{ sivor } \\
\hline & 1 & $\mathbf{z}$ & 3 & 4 & 啮 & \\
\hline 1 & 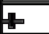 & 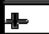 & 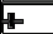 & +1 & 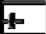 & 5 \\
\hline 2 & 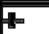 & $E$ & 5 & 1 & 5 & 4 \\
\hline$\overline{8}$ & $\bar{E}$ & E & $\overline{5}$ & E & $\bar{E}$ & $\overline{11}$ \\
\hline 4 & 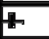 & 4 & $E$ & 5 & 5 & 鸟 \\
\hline 5 & - & $E$ & $E$ & $E$ & 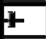 & 1 \\
\hline$\sqrt{\sqrt{5}}$ & $E$ & $=$ & $E$ & 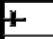 & 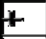 & 可 \\
\hline 7 & $y$ & $=$ & 5 & - & 5 & 1 \\
\hline S & 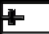 & 5 & 5 & 5 & 5 & ? \\
\hline 氨 & + & t & th & E & E & 2 \\
\hline 10 & $F$ & 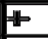 & 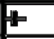 & 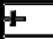 & $E$ & 4 \\
\hline 11 & 8 & A & 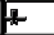 & th & 7 & 5 \\
\hline 15 & 8 & $\Psi$ & 4 & 1 & 1 & 昰 \\
\hline 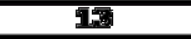 & + & $\Psi$ & $E$ & - & - & 8 \\
\hline 14 & 世눈 & 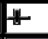 & 落 & $E$ & 4 & 5 \\
\hline 5 & 4 & $\Psi$ & 4 & 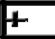 & 4 & 5 \\
\hline 18 & 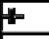 & - & - & - & 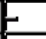 & 1 \\
\hline 17 & - & $E$ & $E$ & 4 & 4 & 2 \\
\hline 18 & - & $E$ & th & 4 & \pm & $z$ \\
\hline 19 & 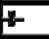 & 4 & 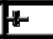 & 5 & $E$ & 5 \\
\hline 29 & 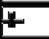 & 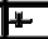 & 4 & E & $E$ & 2 \\
\hline
\end{tabular}

Keherangers:

+ = Artirgra elfitarima

- = Artirgra enlifolak

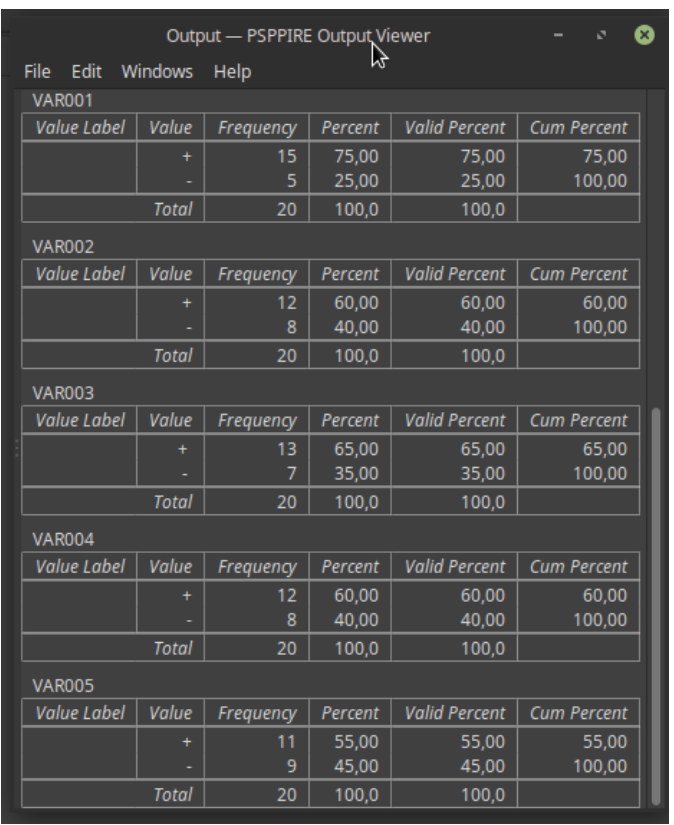

Gambar IV.2. Analyze Frequency GNU PSPP

Jumlah respon diperoleh dengan mengalikan jumlah responden dengan jumlah pernyataan, dalam hal ini $20 \times 5=100$. Jumlah penyimpangan VAR001 5 buah, jadi berikut hasilnya :

$$
\mathrm{KR}=1-\frac{5}{100}=0,95
$$


Berikut hasil perolehan variabel 002 sampai dengan 005, menghasilkan nilai diatas nilai 0,91. Dihitung menurut (Rumus Guttman $K R$ itu hendaknya harus 0,90 atau lebih). Jadi skala yang KR-nya 0,95 dapat dipercaya.

\section{E. KESIMPULAN}

Kesimpulan yang dapat diambil dari hasil penelitian ini adalah adanya pengaruh fungsi pengaruh yang jelas. Berikut hasil yang dapat kami simpulkan:

1. Warna cat menjadikan desain mobil mempunyai ciri khas dan sisi keindahan.

2. Fakta adanya pengaruh warna cat terhadap penentuan harga jual mobil adalah harga dari tiap jenis catnya sendiri dan dari warna yang digunakan.

3. Suatu kajian tentang varian warna cat dengan pemberian data kuantitatif, menguji hipotesi dan untuk mengetahui taraf perbedaan sikap atau sifat individu atau kelompok.

Saran selanjutnya, bisa dilakukan pengembangan lagi mengenai penelitian ini, diantaranya :

1. Pengukuran fakta dengan jumlah lebih banyak secara ilmu sosial dintentukan dalam kontinuum atau skala, yaitu suatu skalam harus valid dan reliable.

2. Metode yang digunakan sebagai bahan acuan tentunya bisa berubah sesuai kondisi yang terjadi, untuk itu diperlukan alat ukur Likert dan Thurstone..

Bahan acuan hanya satu produsen mobil, pengembangannya degnan mencari data pengaruh warna cat pada produsen lain.

\section{DAFTAR PUSTAKA}

[1] Alhilman, Judi (2013). E-Learning Tentang Bab Mengenai Uji Hipotasis Statistik. YouTube 11 Desember 2013. $<$ https://www.youtube.com/watch?v=79g6 GHvUV4g>

[2] Fajar Sidik, Achmad, Perdana, Brian Gustiar, Pratama, Oktavi Nandar, Profiliana, Hera. (2018). Koresponensi Matriks SWOT. Mahasiswa/i Manajemen Informatika AMIK BSI : Purwokerto.

[3] Hidayat Muhammad Nur \& Edi Rakhman (2015). Pemilihan strategi network operations partner Menggunakan metoda swot-ahp untuk potensi pasar E-bisnis pariwisata di barlingmascakeb. Tesis STMIK Nusa Mandiri Jakarta.
[4] Indonesia, Honda (2017). Model HR-V. Lot 2-1, Incubator 1, Technology Park Malaysia.<https://www.hondaindonesia.com $/ \mathrm{model} / \mathrm{hr}-\mathrm{v}>$

[5] La, Eka (2018). Uji Hipotesis Korelasi atau Hubungan Dua Variabel (Tutorial Statistik). YouTube $8 \quad \mathrm{Mei}$ 2018.<https://www.youtube.com/watch?v $=y S F u A 0$ vX8w>

[6] Rangkuti, Freddy (2006). AnalisisSWOT Teknik Membedah Kasus Bisnis: Reorientasi Konsep Perancangan Strategis untuk Menghadapi Abad 21. PT. Gramedia Pustaka Utama, Jakarta.

[7] Nasution S. (2004). Metode Research. Penelitian IImiah, 78. PT. Bumi Aksara : Jakarta.

[8] Psppire 0.8.5. (2007). A Program for the Analysis of Sample Data : Free Software Foundation. <https://www.gnu.org/softwar e/pspp/>

[9] Sugiyono. (2004). Metode Penelitian. Bandung: Alfabeta.

[10] Tips, Aneka Harian (2014). Situs Web Pribadi Tipssupaya, Powered Blogger.

[11] Wijaya, Rendi Yancahya (2018). Manastika. Yogyakarta <www.bahasaotomotif.com>

[12] Zaky, Bukalapak (2018). Harga Jenis dan Varian Cat Mobil. PT. Bukalapak.com<www.Bukalapak.com 